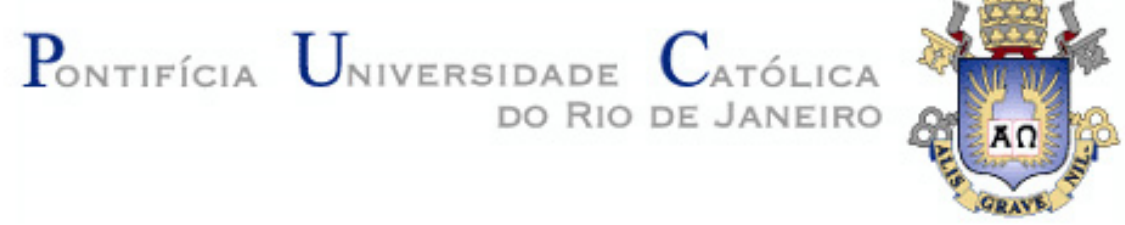

Caroline Conte Reis

Valuation de uma Empresa Familiar:

Um Comparativo de Três Métodos

Dissertação de Mestrado

Dissertação apresentada como requisito parcial para obtenção do grau de Mestre pelo Programa de Pósgraduação em Administração de Empresas do Departamento de Administração de Empresas da PUC-Rio.

Orientador: Prof. Marcelo Cabús Klötzle 
Caroline Conte Reis

\section{Valuation de uma Empresa Familiar: Um Comparativo de Três Métodos}

Dissertação apresentada como requisito parcial para obtenção do grau de Mestre pelo Programa de Pós-Graduação em Administração de Empresas da PUC-Rio. Aprovada pela Comissão Examinadora abaixo.

Prof. Marcelo Cabús Klötzle

Orientador

Departamento de Administração - PUC-Rio

Prof. Henrique Castro Martins

Departamento de Administração - PUC-Rio

Prof. Carlos de Lamare Bastian Pinto

Departamento de Administração - PUC-Rio

Prof. Paulo Vitor Jordão da Gama Silva Universidade do Grande Rio

Rio de Janeiro, 27 de março de 2020 
Todos os direitos reservados. É proibida a reprodução total ou parcial do trabalho sem autorização da universidade, da autora e do orientador.

\section{Caroline Conte Reis}

Graduou-se em Administração de Empresas pela PUC-Rio em 2004. Pósgraduada em Marketing pela PUC-Rio em 2005. Pós-graduada em Finanças Corporativas pela PUC-Rio em 2018.

Ficha Catalográfica

Reis, Caroline Conte

Valuation de uma empresa familiar : um comparativo de três métodos / Caroline Conte Reis ; orientador: Marcelo Cabús Klötzle. 2020.

52 f. ; $30 \mathrm{~cm}$

Dissertação (mestrado)-Pontifícia Universidade Católica do Rio de Janeiro, Departamento de Administração, 2020.

Inclui bibliografia

1. Administração - Teses. 2. Valuation. 3. Fluxo de caixa descontado. 4. Empresa familiar. 5. Método contábil. 6. Avaliação por Múltiplos. I. Klötzle, Marcelo Cabús. II. Pontifícia Universidade Católica do Rio de Janeiro. Departamento de Administração. III. Título. 


\title{
Agradecimentos
}

\begin{abstract}
À minha família, pelo apoio e incentivo ao longo deste curso.
À todos os meus professores que tive ao longo de minha vida, especialmente aos professores da minha querida PUC-Rio, que contribuíram cada um do seu jeito, para que eu conseguisse adquirir todo o conhecimento que tenho hoje. Muito obrigada!
\end{abstract}




\section{Resumo}

Reis, Caroline Conte; Klötzle, Marcelo Cabús. Valuation de uma Empresa Familiar: um Comparativo de Três Métodos. Rio de Janeiro, 2020. 51 p. Dissertação de Mestrado - Departamento de Administração, Pontifícia Universidade Católica do Rio de Janeiro.

O presente estudo ilustra os principais métodos usados no mercado e na academia para valorar uma empresa familiar de capital fechado. A Avaliação pelo Método Contábil, o Fluxo de Caixa Descontado e a Avaliação por Múltiplos são os métodos mais utilizados e serão abordados passo a passo em um estudo de caso para se identificar qual deles melhor se adequa à realidade da empresa alvo com o intuito de se obter um valor econômico financeiro justo. A empresa alvo ficará em sigilo por uma questão de estratégia, possibilitando assim, um possível venda total ou parcial.

\section{Palavras-chave}

Valuation; Fluxo de Caixa Descontado; Empresa Familiar; Método Contábil; Avaliação por Múltiplos 


\section{Abstract}

Reis, Caroline Conte; Klötzle, Marcelo Cabús (Advisor). Valuation of a Family Company: a Comparisson of Three Methods. Rio de Janeiro, 2020. 51 p. Dissertação de Mestrado - Departamento de Administração, Pontifícia Universidade Católica do Rio de Janeiro.

This study presents the main valuation methods often used in the market and in the research fields for small family companies. Accounting Valuation, Discounted Cash Flow and Multiples Method are the most used methods and they will be explained step by step in a study case that will point out which one is the most suitable one for the company. The company will remain confidential as a way of assuring its strategies and a future sale.

\section{Keywords}

Valuation; Discounted Cash Flow: Accounting Valuation; Family Company; Multiples Method. 


\section{Sumário}

$\begin{array}{ll}\text { 1. O problema } & 10\end{array}$

1.1. Introdução 10

1.2. Objetivo Principal 11

1.3. Objetivos Intermediários 11

1.4. Delimitação do Estudo 12

1.5. Relevância do Estudo 12

2. Referencial Teórico 13

2.1. Risco e Retorno 13

2.2. Avaliação Empresarial (Valuation) 14

2.3. Avaliação Contábil 15

2.4. Método de Fluxo de Caixa Descontado 16

$\begin{array}{ll}\text { 2.4.1. Construção dos Fluxos de Caixa } & 17\end{array}$

2.4.1.1. Fluxos de Caixa Realizados 17

$\begin{array}{lc}\text { 2.4.1.2. Fluxos de Caixa Projetados } & 18\end{array}$

2.4.2. Taxa de Desconto 19

2.4.3. Cálculo do Valor Presente do Fluxo de Caixa Projetado 23

2.4.4. Cálculo do Valor Residual e Taxa de Crescimento 24

2.5. Método de Avaliação pelo Modelo de Múltiplos 25

2.5.1. Empresas Comparáveis 26

2.5.2. Variável Comparável 26

2.5.3 Estimação do Valor Empresarial 27

3. Metodologia 28

3.1. Tipos de Pesquisa 28

3.1.1. Quanto aos Fins 28

3.1.2. Quanto aos Meios 29

3.2. Universo e Amostra 29

3.3. Procedimentos e Instrumentos de Coleta de Dados 29

3.4. Tratamento dos Dados 30

3.5. Limitações do Estudo (Limitações do Método) 30 
4. Resultados 31

4.1. A Empresa 31

4.1.2 Avaliação do Macroambiente 31

4.2. Descrição dos Resultados 32

4.2.1. Método Contábil 32

4.2.2. Fluxo de Caixa Descontado 33

4.2.2.1. Elaboração dos Fluxos de Caixa Realizados 34

4.2.2.2. Projeção do Fluxo de Caixa Livre para os Acionistas (FCLS) 35

4.2.2.3. Taxa de Desconto 37

4.2.2.4. Taxa de Crescimento e Valor Terminal 40

4.2.2.5. Valor Presente do Fluxo de Caixa e Valor Empresarial 40

4.2.3. Avaliação por Múltiplos 41

4.2.3.1. Determinação da Empresa Comparável 42

4.2.3.2. Determinação da Variável de Comparação 42

4.3. Análise e Interpretação de Resultados 43

5. Conclusão 46

5.1. Sugestões e Recomendações para Novas Pesquisas 46

6. Referências Bibliográficas $\quad 48$ 


\section{Lista de Tabelas}

Tabela 1: Construção do Fluxo de Caixa Livre para os Sócios 17

Tabela 2: Relação da Variável Beta e Retorno Esperado 22

Tabela 3: Evolução do PL da empresa entre 2016 e 2018 (R\$ mil) 32

Tabela 4: Fluxo de Caixa Realizado entre 2016 e 2018

Tabela 5: Fluxo de Caixa Projetado entre 2020 e 2025

Tabela 6: Composição do Custo de Capital Próprio (em\%) 39

Tabela 7: Valor Empresarial da Empresa pelo FCD 41

Tabela 8: Valor Empresarial da empresa em 2018 


\section{O problema}

\subsection{Introdução}

Oscar Wilde (1890) definiu o cínico como alguém que "sabe o preço de tudo e o valor de nada". O bom negócio seria não se pagar mais por algo que seu valor justo. Porém, há um conflito: o vendedor quer sempre o maior preço que ele pode obter de uma venda e o comprador quer sempre pagar o mínimo possível na negociação. Obras de arte talvez tenham uma influência da percepção do observador do que é valor para ele, algo talvez mais subjetivo. Mas, o que seria um valor justo para um ativo financeiro?

Damodaran (1957), diz que os ativos financeiros devem ser adquiridos com base na expectativa dos fluxos de caixa a serem recebidos no futuro.

No Brasil, a maior parte das empresas é de capital fechado (World Bank, 2019), o que dificulta uma avaliação sobre seus valores justos, pois, diferentemente das empresas de capital aberto, as informações financeiras não são públicas ou estão disponíveis de forma não padronizada, e muitas vezes, não seguem os padrões e modelos do mercado financeiro. Apesar do contínuo esforço do BNDES em 2019, pequenas empresas ainda têm mais dificuldade para conseguir crédito junto aos bancos do que as empresas maiores. Há uma enorme dificuldade na concessão de crédito por questões óbvias de garantias e risco do negócio, refletindo em juros muito altos e muita burocracia. Adicionando a este cenário, temos uma concentração bancária muito grande no país, onde apenas poucos bancos detém todo o dinheiro disponível. Somente empresas grandes têm maior poder de barganha e garantias para fornecerem aos bancos que são muito exigentes.

$\mathrm{Na}$ literatura, as empresas de capital aberto são mais estudadas, porque há maior facilidade ao acesso às informações. A grande questão não é saber todos os modelos matemáticos, as fórmulas e os softwares, mas sim, achar as informações dentro das empresas de capital fechado. Portanto, esse é o grande problema que fez 
surgir a necessidade de se fazer este estudo: uma empresa pequena, familiar, de capital fechado, com mais de 50 anos no mercado brasileiro, que precisa ser avaliada para que um destino em um futuro próximo, seja traçado. Por questões, estratégicas, a empresa em questão deste estudo ficará oculta. Somente dados e informações imprescindíveis serão disponibilizados.

\subsection{Objetivo Principal}

O objetivo deste estudo é apresentar os principais métodos de avaliação empresarial e identificar, através de um estudo de caso, o que melhor se adequa à realidade da empresa em questão. Este estudo utilizou os métodos mais requeridos no mercado e na Academia: Avaliação Contábil, Fluxo de Caixa Descontado e Múltiplos (Martelanc, 2005). Cada método obteve um resultado diferente, demonstrando cada uma de suas peculiaridades e nuances.

\subsection{Objetivos Intermediários}

- Apresentar os três principais métodos de avaliação empresarial, apontando vantagens e desvantagens de cada um.

- Analisar diferentes metodologias para cada modelo e demonstrar a que se adapta melhor à realidade da empresa alvo.

\subsection{Delimitações do Estudo}

A presente pesquisa trata especificamente da investigação do valor empresarial da empresa alvo. A empresa se caracteriza como um negócio familiar cujo capital social é composto pelo único fundador, ou seja, empresa de capital fechado. Portanto, propõe-se a análise do valor da empresa através dos métodos mais praticados pelo mercado.

Os métodos mais utilizados no Brasil para avaliar empresas em geral são: Fluxo de Caixa Descontado, o Modelo de Avaliação por Múltiplos e o Modelo de Avaliação baseado no Valor Patrimonial ou Contábil (Martelanc, 2005). Assim, pretende-se comparar os modelos e resultados obtidos por cada um destes três modelos, apontando suas respectivas vantagens e desvantagens. 
Embora relevante, não se pretende abordar outros métodos como o Valor Econômico Agregado (EVA) ou Opções Reais. A proposta deste trabalho é atingir empreendedores e gerentes de empresas pequenas brasileiras, e assim, julga-se necessário apresentar da forma mais simples possível os principais métodos. a partir deste ponto pode-se partir para modelos mais complexos, mas, este estudo entende que o domínio completo dos principais métodos básicos de avaliação empresarial é mais importante do que uma revisão superficial de diversos métodos.

\subsection{Relevância do Estudo}

Este estudo delimita-se à identificação do método de avaliação de empresas mais adequado para a obtenção de um valor justo para a empresa alvo. No Brasil, somente 334 empresas possuem capital aberto na Bolsa de Valores (World Bank, 2019), o que demonstra que a maioria das empresas naquele país é de capital fechado. Isso dificulta bastante o encontro de possíveis investidores com empresas de capital fechado que desejam aporte de capital ou a venda total de seus ativos.

A empresa em questão neste estudo, é mais uma das inúmeras no país que desejam compreender o valor de seu negócio e tomar a melhor decisão estratégica para dar um destino ao negócio. Acredita-se que o mais importante e desafiador neste estudo seja juntar todos os dados necessários, visto que uma empresa pequena não tem os procedimentos, normas, estrutura e organização, por exemplo, de uma empresa listada na Bovespa. Neste caso, a falta de um planejamento de sucessão do dono e fundador, fez com que os herdeiros se preocupassem em fazer a melhor escolha em relação ao ativo em questão, o que passa obrigatoriamente, por sua avaliação como bem. Por esta razão este estudo é muito relevante não somente para os herdeiros, mas, para todos os colaboradores da empresa. 


\section{Referencial Teórico}

\subsection{Risco e Retorno}

A compreensão do conceito de risco e retorno é primordial para qualquer passo que se dê em finanças, seja na área acadêmica, ou seja na área prática. Sendo assim, em avaliação de empresas não é diferente, é a base de tudo. O retorno de um ativo é a motivação básica para qualquer investidor se interessar ou não, por um ativo. E cada ativo tem um nível de risco envolvido que representa o grau de incerteza da concretização do retorno esperado. Markowitz (1959) argumenta que não é possível alcançar um entendimento de todas as forças econômicas a ponto de se prever com $100 \%$ de certeza o retorno de um investimento. Mesmo com condições econômicas favoráveis, influências de forças não econômicas podem mudar inteiramente o curso de determinado ativo ou o sucesso de um empreendimento.

Portanto, em um entendimento superficial poderia se deduzir que um investidor se sentirá mais inclinado a escolher ativos de menor risco, dado que apresenta maior previsibilidade em seus retornos. Porém, Sharpe (1964), argumenta que existem indivíduos que escolherão ativos de maior risco, caso o retorno esperado seja maior do que os ativos de menor risco percebido.

Markowitz (1959) complementa que a escolha entre um portfólio de maior retorno e maior risco e de um de menor retorno e menor risco irá depender exclusivamente da propensão em assumir riscos de cada investidor. Assim, podese concluir que indivíduos com maior aversão a risco devem sacrificar maiores retornos em busca de menores níveis de incerteza; enquanto indivíduos com menor aversão a risco devem escolher seus investimentos de maneira oposta.

Logo, a variável risco é algo primordial em qualquer decisão financeira. Cada investidor deve analisar não só o nível de risco, mas, também cada tipo de risco que haverá ao longo de todo o processo de investimento. Amaral (2015) cita os tipos de risco existentes:

i. Risco de Crédito: risco de um ativo ou empréstimo se tornar todo ou em parte irrecuperável no caso de default. 
ii. Risco de Mercado: risco associado a instrumentos financeiros transacionados em mercados próprios e/ou por transações em mercados de reduzida liquidez (taxa de juros, taxas de câmbio, preços/commodities, cotações ações/ trading e risco imobiliário).

iii. Risco de Liquidez: falta de liquidez para fazer face aos compromissos assumidos (fluxos de caixa/Mismatchings, concentrações).

iv. Risco Operacional: risco associado às falhas da inadequação de processos, pessoas e sistemas de informação (fraude/erros/processos de tecnologia da informação, segurança e ambiente).

v. Risco Negócio/Estratégia: alterações no mercado (decisões/estratégias).

vi. Reputação: percepção negativa da imagem do ativo (imagem pública)

vii. Legal/ Compliance: violação de regulamentos (normas/regras/jurídico).

viii. País/Soberado: risco de default de um Estado (perturbações políticas).

ix. Fundo de pensões: contribuições não previstas (desvalorização do fundo).

x. Solvência: incapacidade de cobrir perdas (capital).

xi. Contágio: contaminação de agentes do setor (de ativos).

xii. Sistêmico: choque financeiro se propagar em todo setor financeiro.

Alguns teóricos de finanças definem o risco considerando exclusivamente o viés negativo do termo. Essa é a visão de Gitman (2004, p.184) ao afirmar que "risco é a possibilidade de perda financeira". Segundo Damodaran (2007 p.16), em finanças o termo risco "refere-se à probabilidade de obtermos um retorno sobre um investimento diferente do retorno esperado". Esta definição apresenta-se como mais abrangente, pois contempla tanto a probabilidade de ganho quanto de perda. Para Assaf Neto (2009, p.218) trata-se de "um conceito voltado para o futuro, revelando uma possibilidade de perda". 


\subsection{Avaliação de Empresas (Valuation)}

Damodaran (1957) diz que saber o valor de um ativo e o que determina seu valor, é pré-requisito para uma tomada de decisão inteligente. Alguns ativos são mais fáceis de avaliar que outros. Os detalhes na avaliação de ativos variam de ativo para ativo e a incerteza associada a diferentes ativos varia de acordo com cada um. O que não se altera são os princípios centrais da avaliação em geral.

Damodaran (1957) também diz que os ativos financeiros devem ser adquiridos com base na expectativa dos fluxos de caixa a serem recebidos no futuro e não por percepções emocionais momentâneas. E a única questão onde não há discussão na avaliação de empresas é o argumento de que haverá investidores futuros que poderiam pagar um preço maior em algum momento à frente, pelo ativo. Isso, segundo o acadêmico, é uma grande bobagem onde o maior bobo poderá ser o mais interessado em vender o ativo.

O princípio norteador da criação de valor para Koller, Goedhart e Wessels (2010), é que empresas criam valor investindo seu capital, seja próprio ou de terceiros, para gerar fluxos de caixa à uma taxa de retorno que exceda o custo de capital da empresa. Assim, quanto mais as empresas aumentam suas receitas e implantam mais capital a taxas atraentes de retorno, mais valor elas criam.

O importante na avaliação de empresas, independentemente da escolha do método, é analisar o histórico de resultados da empresa, seu mercado e suas perspectivas futuras. Segundo Pratt (1989, apud SAURIN, 2007), existem três perfis distintos de avaliação de empresas. O primeiro perfil, seria o valor justo de mercado da empresa no mercado aberto, o segundo, seria o valor do investimento que representa o valor da empresa sob a percepção dos investidores interessados e o último seria o valor justo, a avaliação financeira atribuída em casos legais ou jurídicos.

Além de se estabelecer a finalidade da avaliação, e escolher o método mais adequado, ainda existe questões como aponta Martins (2000), ligadas a questão de definições de premissas diferentes num mesmo método de avaliação de empresas, o que pode levar a avaliações distintas. Correia (2005) ainda ressalta que cada empresa contém suas próprias peculiaridades, dentro de diferentes indústrias, que podem e devem ser incorporadas aos modelos de avaliação. 
Mais além, a imparcialidade do avaliador é essencial para que o valor do ativo seja representado de forma adequada.

\subsection{Avaliação Contábil}

A avaliação contábil é a forma mais simples de se avaliar o valor de uma empresa. Ela é feita através da apuração do valor do Patrimônio Líquido do negócio no período mais recente (ASSAF NETO, 2003 apud CORREIA, 2005).

Isto é feito através da soma dos itens contábeis que compõem o Patrimônio Líquido, definidos pela Lei número 11.638 de 28.12.2007, como o capital social, reservas de capital, ajustes de avaliação patrimonial, reservas de lucros, ações em tesouraria e prejuízos acumulados (BRASIL, 2019). GITMAN (2004) define Patrimônio Líquido como os direitos financeiros dos sócios da organização.

Há ainda a resolução do Conselho Federal de Contabilidade CFC número 847/99, “o Patrimônio Líquido compreende os recuros próprios da Entidade e seu valor é a diferença entre o valor do Ativo e o valor do Passivo (Ativo menos Passivo). Portanto, o valor do PL pode ser positivo, nulo ou negativo." (CONSELHO FEDERAL DE CONTABILIDADE, 1999).

Apesar da metodologia deste modelo ser simples, ele é apenas um passo inicial para uma avaliação mais profunda. Pois, as informações contábeis são apenas um retrato de um momento da empresa no tempo. Assim, argumenta Fernandez (2001), que nas informações contábeis não aparecem os contratos da empresa, o capital intelectual, a situação da indústria, problemas organizacionais, o valor do dinheiro no tempo e uma possível evolução futura da empresa, tudo é apenas um momento estático que a empresa se encontra, descrito em informações financeiras.

\subsection{Método de Fluxo de Caixa Descontado}


O método de Fluxo de Caixa Descontado (FCD) determina o valor justo de um empreendimento através da projeção dos fluxos de caixa a serem gerados nos próximos períodos descontados posteriormente a uma taxa adequada ao risco representado pelo negócio (DAMODARAN, 2005). A lógica que atua neste modelo é que o investidor vai comprar um negócio ou parte dele, pela riqueza que que o ativo trará no futuro, além de remunerar o capital investido na compra do negócio, ou seja, no poder de ganho da empresa. Os investidores pagam pelo desempenho que esperam obter da empresa no futuro.

O modelo de fluxo de caixa descontado é citado pela literatura como sendo um dos mais utilizados em avaliação de empresas, particularmente quando se objetiva mensurar o desempenho das ações no mercado acionário e, como consequência, traçar as politicas de aquisição, venda ou manutenção de investimentos (SOUTE, 2008). Contudo, o modelo de FDC requer maior domínio do estudo das finanças do que o modelo contábil, pelo fato de seu método exigir a estimação de variáveis e projeções futuras. Por esta razão, é preciso compreender a empresa a fundo, como a indústria que se insere o negócio, os balanços financeiros mais recentes e as estratégias para a empresa feitas pela diretoria para os próximos anos. Portanto, esse método exige uma análise econômica- financeira da empresa para determinar as premissas que ditarão as estimações e projeções.

Além disso, Damodaran (2005) aponta que o modelo de FCD possui inúmeras variações, geradas por duas principais vertentes: o Modelo de Fluxo de Caixa Livre para os Sócios (FCLS) e o Modelo de Fluxo de Caixa Livre para a Firma (FCLF). A principal diferença entre os dois métodos é que o FCLF avalia o valor da empresa a partir do fluxo de caixa sob a ótica dos credores, sejam eles terceiros ou capital próprio. Ou seja, esse fluxo demonstrará o montante disponível para cobrir todas a dívidas e dividendos. Já o FCLS apresenta a ótica do acionista, demonstrando o fluxo de caixa após o pagamento de dívidas com terceiros, a fim de determinar o valor remanescente para remunerar os acionistas.

A empresa analisada neste estudo é de capital fechado, portanto, este estudo optou pelo modelo FCLS. Damodaran (2005) reintera que este modelo é o mais completo por refletir exatamente acionistas de empresas de capital aberto como o dono de uma empresa privada. 
Apesar de se diferenciarem em algumas particularidades como definições de fluxo de caixa e taxa de desconto, o modelo de FCLF e o modelo FCLS possuem a mesma metodologia e raciocínio lógico. Saurin (2007), argumenta que a metodologia clássica da teoria de finanças para se determinar o valor econômico de uma empresa, com base no FCD, é formada pelos seguintes fatores fundamentais:

a) Fluxo de Caixa Projetado, que se pode conceituar como uma simulação com base em dados financeiros da empresa que gerarão caixa, como vendas, margens, estruturas de custos, entre outros.

b) Taxa de Desconto, usada para trazer os fluxos de caixa futuros a valor presente.

c) Valor Residual, que representa a perpetuidade da empresa. Empresas com fluxos de caixa pequenos, por causa de despesas em pesquisas, por exemplo, terão a maior parte de seu valor no valor residual.

\subsubsection{Construção dos Fluxos de Caixa}

\subsubsection{Fluxos de Caixa Realizados}

Antes de realizar qualquer projeção, é necessário construir os fluxos de caixa dos períodos passados: os fluxos realizados. Como já definido, neste estudo será usado o método de Fluxo de Caixa Livre para os Sócios (FCLS). Martelanc (2010) apresenta o modelo para elaboração da seguinte forma:

Tabela 1:

Construção do Fluxo de Caixa Livre para os Sócios

$(=) \quad$ Receitas

(-) Tributos sobre a receita

(-) Custos

(-) Despesas Operacionais

(=) EBTIDA/LAJIDA

(-) Depreciação, Exaustão e Amortização

(=) EBIT/LAJIR

(-) IR sobre Operações

(=) Lucro Operacional após IR (NONPAT) 
(+) Depreciação, Exaustão e Amortização

(-) Imobilizações

(+/-) Variação do Capital de Giro

(=) Fluxo de Caixa Livre para a Empresa (FCLE)

$(-) \quad$ Juros

(+) IR sobre Juros (Benefício Fiscal)

(=) Fluxo de Caixa Livre para os Sócios (FCLS)

Nota. Fonte: Tabela adaptada de Moisés Ferreira da Cunha (2011).

A tabela acima deve ser preenchida com os dados financeiros da empresa nos períodos passados para o desenvolvimento das projeções de fluxo de caixa futuros.

\subsubsection{Fluxos de Caixa Projetados}

Segundo Garrán (2006), estimar os fluxos de caixa futuros de um ativo é o primeiro passo para a determinação do valor presente desse ativo. Ao avaliar empresas, por exemplo, os analistas fazem projeções de vendas futuras que poderão permitir à empresa auferir um retorno esperado em relação ao capital investido no empreendimento. Porém, tal autor também chama atenção pelo fato da incerteza em relação ao montante de vendas previstas nas projeções. O processo de estimação requer um estudo profundo do histórico financeiro da empresa e o ambiente de risco que a cerca. Porém, não há $100 \%$ de certeza que as estimativas se concretizarão da forma esperada. Um fator importante a ser destacado é a necessidade da coerência entre fluxos de caixa e taxas de desconto. Se os fluxos de caixa projetados estão em moeda nominal, a taxa de desconto para tais fluxos também deverá ser nominal. Se esses fluxos dizem respeito ao fluxo de caixa livre para o acionista, eles devem ser descontados pela taxa do custo de capital próprio.

Cerbasi (2003) defende que a projeção dos balanços e fluxos de caixa deve se basear no cenário mais provável para cada uma das seguintes variáveis abaixo:

a) Volume de vendas e preços

b) Impostos 

c) Custos relevantes
d) Investimentos
e) Cenário

O horizonte de projeção a ser analisado é algo muito importante do modelo. Ele não requer um tempo mínimo, porém, Damodaran (2006) enfatiza que quanto maior o horizonte de projeção, mais problemas e incertezas na avaliação do ativo. Por isso, o autor aponta que se puder fazer uma projeção mais curta, melhor. Todavia, Assaf Neto (2006) argumenta que a projeção deve captar minimamente a fase de crescimento do negócio. Titman e Martin (2011), aconselham um horizonte entre três a cinco anos.

\subsubsection{Taxa de Desconto}

A taxa de desconto reflete o valor presente dos fluxos de caixa futuros que um negócio pode gerar. Damodaran (2006) enfatiza que ativos mais arriscados serão descontados a taxas de descontos mais altas enquanto ativos menos arriscados serão descontados a taxas mais baixas. Analistas financeiros e acadêmicos concordam que os fluxos de caixa projetados devem ser calculados usando o custo ponderado de capital ("WACC"). Brigham e Ehrhardt (2017), declaram que o WACC reflete o custo de oportunidade para todos os envolvidos no aporte financeiro do negócio e que o desconto pelo WACC leva em consideração que os fluxos de caixa livre representam o caixa da empresa após todas as despesas exceto o pagamento de dívidas (próprias ou de terceiros). Portanto, o WACC é o custo efetivo de tais dívidas, porque refletirá mais fielmente o valor presente dos fluxos projetados.

Brigham e Ehrhardt (2017), demonstram a fórmula do WACC (custo médio ponderado de capital na equação 2.1:

$$
\mathrm{WACC}=(\mathrm{Ke} \times \mathrm{WPL})+(\mathrm{Ki} \times \mathrm{WP})
$$

Onde:

$\mathrm{Ke}=$ custo de oportunidade de capital próprio

$\mathrm{WPL}=$ a proporção de capital próprio empregado na empresa

$\mathrm{Ki}=$ representa $\mathrm{o}$ custo de capital de terceiros 
$\mathrm{WP}=$ representa a proporção de capital de terceiros empregada na empresa

A segunda metade desta fórmula não demonstra dificuldade, pois, o custo de capital de terceiros pode ser identificado pelas taxas de empréstimos dos bancos e instituições financeiras às empresas ou nas próprias emissões de títulos de dívida no mercado. Somente se chama atenção para o benefício fiscal concedido às empresas com dívidas de terceiros, porque os juros das amortizações ajudam a diminuir o lucro tributável. Portanto adiciona-se na equação o benefício físcal, resultando em: (Ki x WP x (1-T)), onde T representa a alíquota do Imposto de Renda da empresa.

Porém, existe maior subjetividade para o cálculo do custo de oportunidade do capital próprio, já que ele representa a taxa de retorno mínima exigida pelo investidor para aceitar ou não, o investimento. Esse cálculo se mostra complexo, pois, não existe um modelo único para ser usado devido a incerteza e risco de cada decisão financeira.

Mais além, os cenários políticos e econômicos influenciam na taxa de juros, inflação, câmbio, PIB, entre outros, fazendo com que o custo de oportunidade do capital próprio varie de economia para economia. Portanto, este estudo prioriza a literatura acadêmica brasileira na análise do custo de oportunidade de investimentos no Brasil.

O maior desafio na aplicação do WACC é que ele foi formulado para se encaixar mais na realidade de empresas de capital aberto, pois estas, têm sua estrutura de capital bem definida, diferentemente de empresas pequenas e de capital fechado. Este estudo seguirá o modelo do fluxo de caixa livre gerado para o acionista (FCLS) descontando a uma taxa que represente unicamente o custo de capital próprio, pela razão da empresa não possuir dívidas com terceiros. Este estudo optou por demonstrar o WACC por ser mais completo, e não somente o CAPM, para servir como modelo para futuros estudos de empresas com dívidas que outros pesquisadores possam se interessar.

Assim, o ponto central da estimação da taxa de desconto é buscar a medida mais adequada que represente o custo de oportunidade do capital próprio do investidor. Um dos modelos mais utilizados no mundo acadêmico e profissional é o modelo CAPM (Capital Asset Pricing Model, criado por William Sharpe em 1964. Fama (2004) aponta que o CAPM é a continuação da teoria de Seleção de 
Portfólios de Markowitz (1959), que argumenta que o investidor sempre irá buscar o maior retorno possível dado sua disposição a correr risco. Não obstante, o modelo CAPM traz uma nova premissa, na qual se tem a possibilidade de investir ou tomar emprestado a uma taxa livre de risco (Rf), disponível para qualquer investidor ou tomador, independentemente do montante financeiro a ser aplicado. A partir destas premissas, conclui-se que um investidor irá tomar algum risco se o retorno esperado do ativo for maior que a taxa livre de risco.

O excedente a ser ganho é chamado de Risk Premium (Prêmio de Risco de Mercado), que representa o bônus a ser ganho por investir em um ativo cujo retorno é incerto. Supondo-se que todas as pessoas têm acesso às mesmas oportunidades de investimentos, tem-se que cada investidor irá escolher o seu portfólio de ativos de acordo com sua propensão a correr risco dado o retorno esperado de seu portfólio. Portanto, o CAPM expõe uma equação que precifica determinado ativo a partir do nível de risco que ele apresenta em relação às oportunidades que o mercado oferece. Fama (2004) expõe tal modelo na equação (2.2):

$$
E(R i)=R \mathrm{f}+\beta[E(R m)-R \mathrm{f}]
$$

Onde:

$\mathrm{E}(\mathrm{Ri})=$ Retorno esperado do ativo

$\mathrm{Rf}=$ Taxa livre de risco

$\beta=$ Medida do risco do ativo em relação ao mercado

$\mathrm{E}(\mathrm{Rm})=$ Retorno esperado do mercado

$[E(R m)-R \mathrm{f}]=$ Prêmio de risco de mercado

É importante destacar que a variável Beta $(\beta)$ representa o risco que o investidor incorre em relação ao mercado de ações. Um ativo com Beta maior que 1 é mais arriscado do que o mercado, BERK e DEMARZO (2009). Esses autores demonstram da seguinte forma:

Tabela 2:

Relação da variável Beta e Retorno Esperado

\begin{tabular}{|ll|}
\hline Beta & Interpretação em relação ao mercado \\
\hline$>1$ & Maior Risco, Maior Retorno Esperado \\
$=1$ & Risco Igual, mesmo Retorno Esperado \\
$<1$ & Menor Risco, menor Retorno Esperado \\
\hline
\end{tabular}


Nota. Fonte: Adaptado de BERK E DEMARZO (2009)

No mercado brasileiro o uso do CAPM exige algumas observações. Pereiro, 2002, apud Cunha, 2011, pondera que a existência de eficiência de mercado em países emergentes é bastante discutível já que esses possuem mercados pequenos, concentrados e sujeitos à manipulação e, portanto, a reta de mercado de títulos, premissa básica na aplicação do CAPM para definir o custo do capital próprio, se torna controversa. Tentativas são feitas para adicionar variáveis ao custo de capital baseado no CAPM para mercados emergentes. Consequentemente, existe um consenso na academia brasileira e mercado corporativo para que se use as estimativas do mercado norte-americano como algo mais adequado ao modelo.

Abordando primeiramente a taxa livre de risco, o protocolo indica a utilização dos juros pagos pelos títulos do Governo para refletir essa taxa. No Brasil, a melhor representação desse índice se dá pela taxa Selic, definida pelo Ministério da Economia (2019) como: "A taxa de juros equivalente à taxa referencial do Sistema Especial de Liquidação e de Custódia (Selic) para títulos federais, (...), aplicável no pagamento, na restituição, na compensação ou no reembolso de tributos federais (...)". Porém, Assaf Neto (2005) declara que o mercado financeiro não considera os títulos públicos brasileiros como livres de risco, além do fato da série histórica da Selic apresentar enorme dispersão. Por isso, o acadêmico sugere a substituição da taxa Selic pela taxa de juros dos papéis emitidos pelo Governo dos Estados Unidos, visto que estes títulos são considerados como investimentos de risco zero no mundo todo. O Brasil é um mercado emergente e por isso, uma variável deve ser acrescentada para refletir essa incerteza: “o Prêmio de risco-país (abr) na equação do modelo CAPM. Assim, a equação do CAPM ajustada a realidade do Brasil seria na equação (2.3):

$$
\mathrm{E}(\mathrm{Ri})=\mathrm{Rf}+\beta[\mathrm{E}(\mathrm{Rm})-\mathrm{Rf}]+\alpha \mathrm{br}
$$

Por conseguinte, a variável "Prêmio de Risco de Mercado" deve seguir a mesma linha de raciocínio da taxa livre de risco e ser representada pelos retornos dos ativos americanos com relação aos títulos de "risco zero" dos Estados Unidos. Cunha (2011), demonstra que tais premissas, tanto em relação ao Prêmio de Risco de Mercado quanto a taxa Livre de Risco, são as mais usadas no Brasil. O modelo 
CAPM predomina nas avaliações, em que tem como premissas: a taxa livre de risco global (EUA) em $67,74 \%$ dos laudos, desses 77,20\% utilizam o T-Bonds 10 ou 30 anos e que na premissa de retorno do mercado ficou evidente o uso do mercado norte-americano como referência, em 82,26\% das avaliações, e uma predominância inferida desse levantamento é a adição, em $88,71 \%$ das avaliações, do risco-Brasil, que utilizam a abordagem do Spread de inadimplência do país para mensurar esse risco, (CUNHA, 2011).

Em relação a variável Beta, existe a questão da empresa neste estudo não ser de capital aberto e assim, não há negociações de títulos ou ações da mesma. A alternativa seria usar um Beta de uma empresa semelhante do mercado americano, (ASSAF NETO, 2008). Este estudo usará o Beta da empresa americana MSA, por ela ser a mais semelhante à empresa alvo. Entretanto, Damodaran (2019) afirma que o Beta sozinho pode não retratar totalmente o risco de uma pequena empresa, então, deve-se adicionar um Prêmio de Risco chamado de "Small Cap Premium" à equação. Essa estimação é feita através dos retornos excedentes que as pequenas empresas tiveram em relação ao mercado (S\&P 600 Small Cap Index).

Assim, a equação final do CAPM se mostra na equação (2.4):

$\mathrm{E}(\mathrm{Ri})=\mathrm{Rf}+\beta[\mathrm{E}(\mathrm{Rm})-\mathrm{Rf}]+\alpha \mathrm{br}+\theta \mathrm{smll}$

\subsubsection{Cálculo do Valor Presente do Fluxo de Caixa Projetado}

O método FCD continua com o cálculo do Valor Presente dos fluxos projetados para os períodos seguintes. Este cálculo foca no desconto de cada geração de caixa a partir do horizonte futuro determinado até o período presente. A equação que representa tal movimento pode ser verificada na equação (2.5):

$$
\begin{aligned}
& V P t=\sum^{\mathrm{n}} F C t /(1+\mathrm{k})^{t} \\
& t=0
\end{aligned}
$$


Onde:

$V P t=$ Valor presente do fluxo no período $\mathrm{t}$

$F C t=$ Valor financeiro do fluxo no período $\mathrm{t}$

$\mathrm{k}=$ Taxa de desconto

\subsubsection{Cálculo do Valor Residual e Taxa de Crescimento}

Apesar de uma empresa avaliada não demonstrar nenhum sinal de que encerrará suas atividades, é preciso representar esse "ïnfinito" através da perpetuidade da empresa. Também chamado de valor residual, que representa o valor de todos os fluxos de caixa após o último projetado. Neste passo, usamos o modelo de Gordon, que estabelece uma taxa de crescimento constante ("g") para os fluxos de caixa na perpetuidade. É importante ressaltar que essa taxa de crescimento "g" deve ser menor que a taxa de desconto estabelecida no modelo de FCD e será aplicada no último fluxo de caixa do horizonte projetado, e em seguida, trazer a valor presente utilizando a taxa de desconto. Abaixo, a equação (2.6):

Valor Residual $=\{[F C t(1+\mathrm{g})] /(\mathrm{r}-\mathrm{g})\} /(1+\mathrm{k})^{t}$

Onde:

$\mathrm{FCt}=$ Valor financeiro do fluxo no último período projetado

$\mathrm{k}=$ Taxa de desconto

$\mathrm{g}=$ Taxa de crescimento em perpetuidade

Após o cálculo do Valor Residual, o valor total da empresa é obtido pelo somatório deste com o valor presente dos fluxos de caixa nos períodos anteriores projetados, de acordo com a fórmula na equação (2.7):

$n$

Valor Empresarial $=\sum \mathrm{FCt} /(1+r)^{\wedge} t+$ Valor Residual

$t=0$ 


\subsection{Método de Avaliação pelo Método de Múltiplos}

A avaliacão por múltiplos é largamente utilizada por financistas como uma das opções para se compreender o valor de uma empresa. O método segue um modelo simples, no qual "o método de avaliação por múltiplos tem como objetivo avaliar ativos com base nos preços correntes de mercado de outros ativos ditos “comparáveis", sendo, portanto, um método de avaliação relativa" (SALIBA, 2005). Ou seja, ativos semelhantes devem apresentar preços semelhantes.

Saliba (2005) ainda ressalta que aspectos como receita, fluxo de caixa e valor patrimonial são as variáveis observadas para a comparação entre empresas. É preciso ter cautela na avaliação por múltiplos porque ela reflete o estado de espírito do mercado num determinado momento, o que pode resultar numa superestimação (valor alto) ou subestimação (valor baixo) do ativo. O risco, o crescimento e potencial fluxo de caixa do negócio não devem ser ignorados para uma avaliação consistente do ativo.

Brandão (2015) declara que a principal vantagem deste modelo é a simplicidade de sua metodologia e a facilidade de compreensão por diferentes profissionais. Além de ser um método baseado em transações de compra/venda já praticadas pelo mercado, minimizando a possível subjetividade vinda de julgamentos pessoais presente em outros métodos.

Damodaran (2005), sugere uma análise corrente do modelo de avaliação por múltiplos a partir dos seguintes passos:

a) Procurar uma empresa com características semelhantes que estejam no mesmo setor, preferencialmente.

b) Definir uma escala entre o valor das duas empresas a partir de uma variável comum, chamada múltiplo.

c) Ajustar o valor do ativo ou empresa a partir do múltiplo.

\subsubsection{Empresas Comparáveis}


Duas empresas podem ser consideradas comparáveis se apresentarem risco, crescimento e fluxos de caixa semelhantes (DAMODARAN, 2005). Ainda assim, pode-se considerar empresas inseridas na mesma indústria como semelhantes, visto que compartilham o mesmo risco, crescimento e fluxo de caixa. $\mathrm{O}$ acadêmico ainda aponta que empresas com similaridades nessas vairiáveis podem ser comparadas, mesmo sendo de indústrias diferentes.

O que ocorre na prática, é que a avaliação por múltiplos em empresas de capital fechado em países em desenvolvimento como o Brasil, se torna um pouco mais difícil. Nesses países, o mercado é menor e não há tantas empresas com características semelhantes com capital aberto. Assim, os dados financeiros do setor não são totalmente conhecidos, pois, tais empresas não são obrigadas a disponibilizar seus números publicamente, há risco político e econômico maior do que em países desenvolvidos, falta governança corporativa e há baixos níveis de liquidez e transações.

\subsubsection{Variável Comparável}

Liu, Nissim e Thomas (2002), apontam que as variáveis mais comumente usadas pelo mercado são: razão P/E (Price/Earnings ou Preço/Resultado em português), Patrimônio Líquido e Receita.

A razão P/E representa o preço da ação com relação aos ganhos gerados pela empresa no último período. Esse índice é largamente usado pelo mercado financeiro porque determina os ganhos que um ativo oferece ao investidor em relação ao preço pago. Esse mesmo raciocínio pode ser usado para se comparar um ativo, segundo Damodaran (2005). Embora a variável "E" deva ser substituída pelo EBITDA (resultado operacional da empesa).

A próxima variável que pode ser usada para a estimação do múltiplo é o valor do Patrimônio Líquido. Essa variável é muito usada por contadores, porém, não por investidores por não representar de forma dinâmica o custo dos ativos DAMODARAN (2005).

Por fim, o uso da receita total que reflete as vendas totais da empresa e não depende de nenhum cálculo. 
Damodaran (2006), defende que independentemente da escolha entre esses três indicadores financeiros, o resultado deve convergir. Porém, Liu, NIssim e Thomas (2002), argumentam a escolha da receita total demonstrou o pior resultado em sua pesquisa e que o índice $\mathrm{P} / \mathrm{E}$ demonstrou melhor resultado.

\subsubsection{Estimação do Valor Empresarial}

Feita a escolha da empresa a ser comparada e da variável a ser utilizada como indicador de referência (múltiplo), o valor da empresa alvo pode ser obtido através da multiplicação do valor da empresa comparável com o múltiplo de comparação das duas empresas. Saliba (2005) define a equação do Modelo de Múltiplos da seguinte equação (2.8):

$P i, t=X i, t \times P \mathrm{j}, \mathrm{t} / \mathrm{Xj}, \mathrm{t}$

Onde:

$P i, t=$ Valor empresarial da empresa alvo no tempo $\mathrm{t}$

$P j, t=$ Valor empresarial da empresa comparável no tempo $\mathrm{t}$

$X i, t=$ Variável escolhida como indicador de referência da empresa alvo

$X j, t=$ Variável escolhida como indicador de referência da empresa comparável 


\section{Metodologia}

\subsection{Tipo de Pesquisa}

O principal objetivo deste estudo é desenvolver uma avaliaçãao de uma empresa pequena, familiar e de capital fechado a partir da aplicação e investigação dos principais métodos praticados pelo mercado (Avaliação Contábil, Fluxo de Caixa Descontado e Método dos Múltiplos). O estudo se dará por meio de um estudo de caso, que possibilita a aplicação de dados reais da empresa em modelos quantitativos propostos.

Segundo Creswell (2010), o estudo de caso é o mais adequado para encontrar respostas para perguntas seguidas de "como" ou "por que". Creswell 2010, apud Stake (1995) ainda afirma que estudos de caso são uma estratégia de investigação em que o pesquisador explora profundamente um programa, um evento, uma atividade, um processo ou um ou mais indivíduos. Os casos são relacionados pelo tempo e pela atividade, e os pesquisadores coletam informações detalhadas usando vários procedimentos de coleta de dados durante um período de tempo prolongado.

Esta dissertação será de natureza mista, pois, ela contém análises quantitativas e uma interpretação qualitativa do processo de construção dos métodos e dos resultados finais gerados pela avaliação empresarial.

\subsubsection{Quanto aos Fins}

O caráter da pesquisa será descritivo porque compara e avalia diferentes métodos de Avaliação de Empresas. Pesquisas descritivas se basiam em: observação, registro, análise, classificação e interpretação dos fatos sem interferência ou manipulação por parte do autor do estudo (Cresweel, 2010).

\subsubsection{Quanto aos Meios}


Primeiramente, para a elaboração deste trabalho, houve uma vasta pesquisa e leitura de artigos acadêmicos (Google Acadêmico, Base Scopus, e Biblioteca Virtual da Puc-Rio) e livros de Finanças sobre o tema central Avaliação de Empresas (Valuation) e na sequência seu referencial teórico para domínio e entendimento do tema.

Em seguida, uma profunda investigação e levantamento das informações financeiras da empresa alvo e o mercado em que ela está inserida, para se aplicar o conhecimento adquirido através do referencial teórico.

\subsection{Universo e Amostra}

O universo desta pesquisa contém empresas semelhantes, ou seja, pequenas, de capital fechado e familiares. A amostra desta pesquisa é composta unicamente pela empresa alvo.

\subsection{Procedimentos e Instrumentos de Coleta de Dados}

Os dados da empresa alvo foram coletados pelo autor desta pesquisa. Os dados são contábeis e gerenciais.

Os dados contábeis Demonstração de Resultado de Exercício e Balanço Patrimonial dos anos: 2016, 2017 e 2018, foram fornecidos pela empresa de contabilidade terceirizada que presta este serviço há muitos anos para a empresa e são os oficiais usados para a declaração de Imposto de Renda pessoa jurídica.

Os dados gerenciais também foram analisados, pois, ajudam a compor os métodos usados neste estudo, como por exemplo: projeções de crescimento anual da receita. Projeções de faturamento, expectativas de crescimento do mercado e novas licitações são informações gerenciais coletadas da empresa. Estes dados foram relatados por alguns colaboradores da diretoria da empresa.

Todas essas informações foram usadas para projetar os fluxos de caixa e para ajudar na montagem do custo de capital da empresa. Como a empresa não possui dívidas, o custo de capital próprio foi o mais desafiador de ser elaborado neste estudo. 


\subsection{Tratamento dos Dados}

Os dados foram fornecidos pela diretoria da empresa e foram alinhados em planilhas de Excel. Não houve qualquer alteração feita. Os modelos de avaliação de empresas foram feitos em planilhas do Excel

\subsection{Limitações do Estudo (Limitações do Método)}

Apesar de viabilizar na prática uma avaliação de uma empresa real do mercado brasileiro, o estudo de caso somente avalia a empresa alvo o que é muito restrito. O modelo ideal no caso da empresa em questão pode não ser o melhor para outra empresa pequena e/ou familiar e/ou do mesmo setor.

Porém, qualquer interessado poderá se beneficiar do entendimento do passo a passo da pesquisa desta dissertação sobre avaliar um negócio. 


\section{Resultados}

\subsection{A Empresa}

A empresa em questão ficará em anonimato por questões de estratégia e confidencialidade. Ela é uma empresa pequena que fabrica EPIs (Equipamentos de Proteção Individual), localizada no Rio de Janeiro, há mais de 50 anos.

\subsubsection{Avaliação do Macroambiente}

A empresa alvo deste estudo está inserida no mercado de EPIs (Equipamento de Proteção Individual). Este mercado está intimamente ligado a praticamente todos os setores de nossa economia porque na maioria deles há a obrigação por lei do uso de EPIs pelo empregado durante a jornada de trabalho. Por um lado, isso é excelente porque há sempre demanda por EPIs, porém por outro lado, quando a economia do Brasil vai mal, como foi nos últimos anos, com um PIB caindo e chegando a negativo, isso é mortal. Exemplos de setores que compram EPIs: o setor de infraestrutura, como o de construção civil, o setor de transformação, como as indústrias de manufaturados em geral, o setor de aviação, o setor de petróleo, entre outros.

Outro momento difícil que a empresa alvo passou além da queda na demanda por conta do mal desempenho da economia brasileira desde 2015, e posteriormente recessão da mesma, foram os aumentos da energia elétrica e da gasolina que tiveram seus preços artificialmente segurados e congelados numa decisão política feita pela ex presidente Dilma durante seu governo, para segurar a inflação durante sua gestão.

Além disso, as matérias primas, como o plástico, também tiveram seus preços aumentados devido as cotações internacionais por serem commodities e consequentemente terem seus preços atrelados ao dólar americano que subiu muito. Em consequência, houve uma diminuição da margem da empresa alvo, e uma grande queda da receita total.

Muitas empresas e negócios nacionais quebraram e as que sobreviveram tiveram muitos prejuízos. A empresa tem usado seu caixa para cobrir os meses negativos nas vendas durante o período de 2016 a 2018. 


\subsection{Descrição dos Resultados}

Este estudo, como citado anteriormente, tem como objetivo principal obter um valor para a empresa alvo através dos três métodos mais usados no Brasil, analisando os resultados e chegando a uma conclusão do valor econômico-financeiro da empresa. Neste caso, esse propósito é fundamentar e argumentar o negócio para uma possível venda. Assim, este estudo servirá como uma base de negociação para um potencial investidor.

Por conseguinte, é necessário a obtenção de um valor justo do négocio, mas, que também capte seu potencial.

\subsubsection{Método Contábil}

Neste método não há grandes dificuldades e sim, mais um entendimento do conceito de Patrimônio Líquido para se obter o valor da empresa.

Tabela3:

Evolução do PL entre 2016 e 2018 (R\$)

Patrimônio Líquido

\begin{tabular}{|lccc|}
\hline & 2016 & 2017 & 2018 \\
Capital Social & $909.300,51$ & $724.777,20$ & $537.668,64$ \\
Capital Integralizado & $303.406,07$ & $303.406,07$ & $300.000,00$ \\
Reservas de Lucros & $605.894,44$ & $421.371,13$ & $237.668,64$ \\
Patrimônio Líquido & $\mathbf{9 0 9 . 3 0 0 , 5 1}$ & $\mathbf{7 2 4 . 7 7 7 , 2 0}$ & $\mathbf{5 3 7 . 6 6 8 , 6 4}$ \\
\hline
\end{tabular}

Nota. Fonte: Tabela realizada a partir dos balanços oficiais da empresa.

A empresa apresentou uma queda em seu Patrimônio Líquido nos últimos anos devido a queda em suas vendas por consequência da grande crise econômica que se instalou no Brasil a partir de 2015. A empresa opera pelo Sistema de Lucro Presumido onde se paga o Imposto de Renda sobre o faturamento, independentemente se houver lucro ou não. Este estudo optou por não expor os Balanços Patrimoniais na íntegra por achar que essas informações são de cunho mais estratégico e íntimo da empresa. A contabilidade da empresa é terceirizada e isto traz um pouco de dificuldade de acesso a detalhes sobre as informações financeiras. A Diretoria 
da empresa, até o presente momento, está retendo muito as informações financeiras no topo da organização.

Portanto, pode-se concluir que o método contábil apesar de ser um método simples, é muito conservador. Ele não reflete o potencial valor do negócio, sua realidade atual, lucratividade e projeções para o futuro. Além disso, desconsidera ativos intangíveis, como marca, reputação, cultura e relações com clientes e fornecedores. A avaliação é baseada em valores passados (ocorridos) e não tem expectativas futuras de resultados. Somando-se a isto, é sabido que patrimônio e valor de vendas são coisas bem distintas e ciências bem diferentes em sua complexidade. Uma grande crítica feita a este método está na dependência total da contabilidade. Isso se dá devido à adoção de critérios na hora do lançamento contábil ou nas práticas que possuem grande nível de erro na montagem da peça final. Estes erros ocorrem nos três regimes tributários utilizados no Brasil: Simples Nacional, Lucro Presumido e Lucro Real. Ademais, a avaliação pelo Método Contábil, é bem subjetiva, e diverge dos critérios de valor de mercado, uma vez que a contabilidade registra as operações através de valores originais, baseadas nos custos de aquisição ou de formação de um ativo. Isso resulta na diferença entre o valor contábil e o valor de mercado da empresa.

\subsubsection{Fluxo de Caixa Descontado}

\subsubsection{Elaboração da Demonstração de Resultados Realizada}

Conforme discutido no referencial teórico, a metodologia do Fluxo de Caixa Descontado da empresa alvo seguirá o modelo FCLS, no qual, demonstra o Fluxo de Caixa Livre sob a perspectiva dos acionistas. Portanto, serão consideradas todas as saídas de caixa que não são levadas em conta no modelo FCLF, como o pagamento de dívida com terceiros, ressaltando assim, o valor remanescente para remunerar os acionistas.

Foram analisadas as bases históricas financeiras das demonstrações de resultados dos anos 2016, 2017 e 2018, para serem as referências na construção da projeção do fluxo de caixa. A empresa alvo trabalha com o sistema de Lucro Presumido, onde o Imposto de Renda é pago 
sobre o faturamento total da empresa independentemente se houver lucro ou não. A tabela 4 demonstra o DRE realizado em milhares de reais.

Tabela 4:

DRE gerencial realizado entre 2016 e 2018 (Método Lucro Presumido)

\begin{tabular}{|c|c|c|c|}
\hline \multirow{2}{*}{ Receita Operacional Bruta } & 2016 & 2017 & 2018 \\
\hline & $5.364 .355,01$ & $5.692 .369,27$ & $6.060 .354,46$ \\
\hline Receita Bruta de & & & \\
\hline Venda & $5.364 .355,01$ & $5.692 .369,27$ & $6.060 .354,46$ \\
\hline (-) Deduções da Receita Bruta & $970.294,70$ & $1.000 .920,14$ & $1.037 .982,95$ \\
\hline $\begin{array}{l}\text { Dedução de Receita Bruta de } \\
\text { Vendas }\end{array}$ & $970.294,70$ & $1.000 .920,14$ & $1.037 .982,95$ \\
\hline Receita Operacional Líquida & 4.394.060,31 & $4.691 .449,13$ & $5.022 .371,51$ \\
\hline Custos das & & & \\
\hline Vendas & $977.506,61$ & $970.417,39$ & $1.319 .696,96$ \\
\hline Custos Diretos de Produção & $106.255,23$ & $143.991,45$ & $173.684,48$ \\
\hline $\begin{array}{l}\text { Custos de Vendas e Despesas } \\
\text { Operacionais }\end{array}$ & $871.251,38$ & $826.425,94$ & $1.146 .012,48$ \\
\hline Resultado Operacional Bruto & $3.416 .553,70$ & $3.721 .031,74$ & $3.702 .674,55$ \\
\hline $\begin{array}{l}\text { Receitas } \\
\text { Financeiras }\end{array}$ & 234,91 & 64,23 & \\
\hline Recuperação & $43.084,92$ & $37.749,06$ & 91342,20 \\
\hline $\begin{array}{l}\text { Diversas } \\
\text { Despesas }\end{array}$ & $43.084,92$ & $37.749,06$ & 91342,20 \\
\hline Operacionais & $485.832,21$ & $1.126 .617,16$ & $1.121 .202,69$ \\
\hline Despesas Gerais Operacionais & $485.832,21$ & $1.126 .617,16$ & $1.121 .202,69$ \\
\hline $\begin{array}{l}\text { Despesas } \\
\text { Financeiras } \\
\text { Despesas }\end{array}$ & $359.544,11$ & $16.029,80$ & $16.651,97$ \\
\hline Financeiras & $359.544,11$ & $16.029,80$ & $16.652,97$ \\
\hline Outras Despesas Operacionais & $2.097 .426,00$ & $2.276 .550,73$ & $2.273176,24$ \\
\hline $\begin{array}{l}\text { Despesa com } \\
\text { Pessoal } \\
\text { Despesas }\end{array}$ & $1.926 .510,00$ & $2.092 .816,35$ & $2.074 .659,42$ \\
\hline Tributárias & $170.916,00$ & $183.734,38$ & $198.516,82$ \\
\hline Resultado Operacional Líquido & $517.071,21$ & $339.647,34$ & $382.985,85$ \\
\hline
\end{tabular}


Receitas Não Operacionais

Despesas Não Operacionais

Lucro Líquido antes do C.S.S.L

C.S.S.L

$517.071,21 \quad 351.893,91 \quad 382.985,85$

Lucro Líquido antes do

Imposto de Renda $\quad 317.071,21 \quad 351.893,91 \quad 382.985,85$

Imposto de Renda

Resultado Líquido do Exercício

$517.071,21 \quad 351.893,91 \quad 382.985,85$

Nota. Fonte: Tabela realizada através das informações financeiras dadas pela empresa.

\subsubsection{Projeção do Fluxo de Caixa Livre para os Acionistas (FCLS)}

Para desenvolver a base de cálculo da projeção do Fluxo de Caixa Livre para os Acionistas é necessário definir algumas premissas:

a) Após grande impacto da recessão econômica no crescimento da receita total nos últimos anos da empresa alvo, o Banco Central do Brasil previu no relatório Focus de dezembro de 2019 uma projeção dos seguintes setores do PIB: 2,3\% para consumo das famílias e 4,1\% para FBCF (Formação Bruta de Capital Fixo), sendo este último associado a prognóstico mais favorável da construção civil. Este estudo trabalhará com a projeção de $4,1 \%$ do FBCF para receitas brutas futuras.

b) Taxa de crescimento nominal da empresa será de 8,41\% a.a. Baseada numa previsão do PIB 2020 de 4,1\%, para o setor, e a inflação do ano de 2019 de 4,31\%,

c) A dedução da receita bruta de vendas será de $18 \%$, custo das vendas $23 \%$ da receita operacional líquida (custos diretos de produção 13\% e custo de vendas e despesas operacionais $87 \%$ da receita operacional liquida). Outras receitas operacionais: $2 \%$, despesas operacionais: $25 \%$, despesas financeiras: $4 \%$ e outras despesas operacionais: $61 \%$ ambas do resultado operacional bruto. Esses múltiplos foram calculados através da média história das informações financeiras obtidas por este estudo nos anos: 2016, 2017 e 2018.

d) Despesas Tributárias, Gerais/Operacionais/Financeiras serão estimadas pela média histórica

e) Não há capital de terceiros 
Este estudo escolherá um horizonte de cinco anos por ser o mais usado no mercado e que consegue capturar um período de crescimento projetado e ao mesmo tempo, diminuir incertezas de períodos muito longos. Este horizonte será conservador. A taxa de perpetuidade será inferior à de crescimento acelerado. O cenário econômico será conservador, apesar da aprovação da previdência, porém ainda, com reformas importantes ainda incertas como a tributária e administrativa do governo.

Portanto, demonstra-se na Tabela 5, o fluxo de caixa projetado de 2020 a 2024, usando a taxa de desconto baseada no custo do capital próprio conforme mostrado na metodologia.

Tabela 5:

Fluxo de Caixa Projetado entre 2020 e 2024

\begin{tabular}{|c|c|c|c|c|c|}
\hline & 2020 & 2021 & 2022 & 2023 & 2024 \\
\hline Receita Operacional Bruta & $6.570 .030,27$ & $7.122 .569,82$ & $7.721 .577,94$ & $8.370 .962,64$ & $9.074 .960,60$ \\
\hline Receita Bruta de Venda & $6.570 .030,27$ & $7.122 .569,82$ & $7.721 .577,94$ & $8.370 .962,64$ & $9.074 .960,60$ \\
\hline (-) Deduções da Receita Bruta & $1.182 .605,45$ & $1.282 .062,57$ & $1.389 .884,03$ & $1.506 .773,28$ & $1.633 .492,91$ \\
\hline Dedução de Receita Bruta de Vendas & $1.182 .605,45$ & $1.282 .062,57$ & $1.389 .884,03$ & $1.506 .773,28$ & $1.633 .492,91$ \\
\hline Receita Operacional Líquida & $5.387 .424,82$ & $5.840 .507,25$ & $6.331 .693,91$ & $6.864 .189,37$ & 7.441.467,69 \\
\hline Custos das Vendas & $1.239 .107,71$ & $1.343 .316,67$ & $1.456 .289,60$ & $1.578 .763,55$ & $1.711 .537,57$ \\
\hline $\begin{array}{l}\text { Custos Diretos de Produção } \\
\text { Custos de Vendas e Despesas }\end{array}$ & $161.084,00$ & $174.631,17$ & $189.317,65$ & $205.239,26$ & $222.499,88$ \\
\hline Operacioanis & $1.078 .023,71$ & $1.168 .685,50$ & $1.266 .971,95$ & $1.373 .524,29$ & $1.489 .037,69$ \\
\hline Resultado Operacional Bruto & $4.148 .317,11$ & $4.497 .190,58$ & $4.875 .404,31$ & $5.285 .425,81$ & $5.729 .930,12$ \\
\hline \multicolumn{6}{|l|}{ Receitas Financeiras } \\
\hline Outras Receitas Operacionais & $82.966,34$ & $89.943,81$ & $97.508,09$ & $105.708,52$ & $114.598,60$ \\
\hline Recuperação Diversas & $82.966,34$ & $89.943,81$ & $97.508,09$ & $105.708,52$ & $114.598,60$ \\
\hline Despesas Operacionais & $1.037 .079,28$ & $1.124 .297,65$ & $1.218 .851,08$ & $1.321 .356,45$ & $1.432 .482,53$ \\
\hline Despesas Gerais Operacioanis & $1.037 .079,28$ & $1.124 .297,65$ & $1.218 .851,08$ & $1.321 .356,45$ & $1.432 .482,53$ \\
\hline Despesas Finaceiras & $165.932,68$ & $179.887,62$ & $195.016,17$ & $211.417,03$ & $229.197,20$ \\
\hline Despesas Financeiras & $165.932,68$ & $179.887,62$ & $195.016,17$ & $211.417,03$ & $229.197,20$ \\
\hline Outras Despesas Operacioanis & $2.530 .473,44$ & $2.743 .286,25$ & $2.973 .996,63$ & $3.224 .109,75$ & $3.495 .257,37$ \\
\hline Despesa com Pessoal & $2.328 .035,56$ & $2.523 .823,35$ & 2.736.076,90 & $2.966 .180,97$ & $3.215 .636,78$ \\
\hline Despesas Tributárias & $186.242,85$ & $201.905,87$ & $218.886,15$ & $237.294,48$ & $257.250,94$ \\
\hline Resultado Operacional Líquido & $497.798,05$ & $539.662,87$ & $585.048,52$ & $634.251,10$ & $687.591,61$ \\
\hline \multicolumn{6}{|l|}{ Receitas Não Operacionais } \\
\hline \multicolumn{6}{|l|}{ Despesas Não Operacionais } \\
\hline Lucro Lïquido antes do C.S.S.L & $497.798,05$ & $539.662,87$ & $585.048,52$ & $634.251,10$ & $687.591,61$ \\
\hline $\begin{array}{l}\text { C.S.S.L } \\
\text { Lucro Lïquido antes do Imposto de } \\
\text { Renda }\end{array}$ & $497.798,05$ & $539.662,87$ & $585.048,52$ & $634.251,10$ & $687.591,61$ \\
\hline
\end{tabular}


Nota. Fonte: Tabela realizada a partir dos dados gerenciais fornecidos pela

diretoria da empresa e premissas definidas por este estudo.

\subsubsection{Taxa de Desconto}

A taxa de desconto no método de Fluxo de Caixa Livre para o Acionista representa o custo de oportunidade do capital próprio. Este estudo obterá esta taxa através do modelo CAPM, conforme citado no referencial teórico. A equação do $\mathrm{CAPM}$ é: $\mathrm{E}(\mathrm{Ri})=\mathrm{Rf}+\beta[\mathrm{E}(\mathrm{Rm})$ -Rf]. Devido a este estudo ser sobre uma empresa de um país emergente, onde há instabilidade poítica e econômica, o CAPM ajustado será: $\mathrm{E}(\mathrm{Ri})=\mathrm{Rf}+\beta[\mathrm{E}(\mathrm{Rm})-\mathrm{Rf}]+\alpha b r+\theta$ smll.

A taxa livre de risco (Rf), foi estimada através do Departamento do Tesouro Americano (2019), para se obter a taxa de juros do título público americano de 30 anos, obtendo-se $2,11 \%$ no dia 6 de fevereiro de 2020, (Departamento de Tesouro dos EUA). Por haver uma perpetuidade, este estudo optou pelo título de maior perpetuidade.

O Prêmio de Risco do Mercado Americano ([E(Rm0-Rf], na equação), será o índice S\&P 500, pois é bastante longo e consistente. A média histórica dos últimos cinco anos foi de 10,45\%, dado obtido no site INVESTING.COM (2020).

O Beta $(\beta)$ usado será o da empresa americana MSA pela sua semelhança com a empresa alvo. Essa informação foi extraída do site INVESTING.COM, (2020), onde o Beta da MSA é de 1,03. Porém, como a empresa alvo deste estudo não possui dívida, esse Beta terá que ser desalavancado através da seguinte equação (4.1):

$\mathrm{Bu}=\mathrm{B} 1\{[1+(1-\operatorname{IRx}(\mathrm{D} / \mathrm{E})]\}$

Onde:

$\mathrm{Bu}=$ Beta desalavancado 
$\mathrm{IR}=$ Alíquota do Imposto de Renda

$\mathrm{D}=$ Dívida de longo prazo

E= Patrimônio Líquido (shareholders equity)

As informações financeiras a seguir, foram extraídas do site da empresa MSA (msasafety.com) em 7 de fevereiro de 2020, e são do ano fiscal mais recente disponível até o presente momento, ou seja, o final de 2018. Usando a fórmula do Beta desalavancado, chegouse a um Beta de 1,39. O cálculo está demonstrado abaixo:

Tabela 5.1:

\section{Cálculo do Beta desalavancado da empresa MSA:}

\begin{tabular}{|c|c|}
\hline Beta alavancado & 1,03 \\
\hline Dívida de LP (\$mil) & 341.311 \\
\hline PL (\$mil) & 639.519 \\
\hline IR & $35 \%$ \\
\hline Beta desalavancado & 0,91 \\
\hline
\end{tabular}

Nota: elaboração própria dos cálculos.

Em relação à variável $\alpha$ br na equação, será usado um dos indicadores mais usados no mercado financeiro para representar o Risco-Brasil, o EMBI+Br (Emerging Markets Bond Index Plus Brazil). Ele é calculado pelo J.P Morgan Chase, e este índice é constituído a partir dos instrumentos financeiros que compõem a dívida externa do Brasil. O site Portal Brasil (2019) fornece as cotações diárias deste índice. A última cotação disponível é de outubro de 2018 e se apresentou nesta data um índice de $2,6 \%$.

Já para o Prêmio Small Caps será usado a indicação de Damodaran (2019), S\&P 600 Small Cap Index para uma comparação com o S\&P 500 Index (usado nesta pesquisa para estimar o Retorno Esperado de Mercado). O índice em 31 de dezembro de 2019 era de 1,48\%, e será usada na composição do CAPM.

A taxa de desconto será, então, composta como segue a tabela abaixo:

Tabela 6: 


\section{Composição do Custo de Capital Próprio (em \%)}

\begin{tabular}{|ccc|}
\hline Variável & Índice & Valor \\
\hline $\mathrm{Rf}$ & Treasury Yield 30 Yr & $2,11 \%$ \\
$\beta$ & BETA MSA Desalavancado & 0,91 \\
$\mathrm{E}(\mathrm{Rm})$ & Retorno Esperado (S\&P500) & $10,45 \%$ \\
Prêmio de Small Caps & S\&P600 Small Cap Index & $1,48 \%$ \\
Risco-Brasil & EMBI+Br & $2,6 \%$ \\
\hline $\mathrm{E}(\mathrm{Ri})=\mathrm{Rf}+\beta[\mathrm{E}(\mathrm{Rm})-\mathrm{Rf}]+\alpha \mathrm{br}+\theta$ smll & Custo de Capital Próprio & $13,78 \%$ \\
\hline
\end{tabular}

Nota. Fonte: Tabela desenvolvida a partir das seguintes fontes: Banco Central do Brasil (2019), Damodaran (2019), Departamento do Tesouro Americano (2019) e Portal Brasil (2019), site Investing.com (2019).

Porém, o custo de capital próprio encontra-se em dólar americano e deve ser convertido para o real brasileiro, segundo a equação (4.2) de GITMAN, (2004):

$i_{\mathrm{BR}}=\left(1+i_{\mathrm{US}}\right) \times\left\{(1+i n f l \mathrm{BR}) /\left(1+\right.\right.$ inf $\left.\left._{\mathrm{US}}\right)\right\}-1$

Onde:

$i_{\mathrm{BR}}=$ Taxa de desconto em $\mathrm{R} \$$

$i_{\text {Us }}=$ Taxa de desconto em US\$

inf $l_{\mathrm{BR}}=$ Inflação brasileira projetada para o período inf $l_{\mathrm{US}}=$ Inflação americana projetada para o período

A projeção de inflação brasileira para 2020 é de 3,56\% (IPCA), segundo o relatório Focus (2020). E a inflação dos EUA será de 2,11\% (OECD, 2020)

Portanto, o CAPM ajustado será de 15,23\% (13,78\%+1,45\%).

\subsubsection{Taxa de Crescimento e Valor Terminal}

A taxa de crescimento "g" deve se apoiar na projeção de crescimento do setor, porém, é difícil dizer que a empresa pode ou não crescer mais que a economia do país, mesmo o negócio da empresa (EPIs) ser intimamente ligado à Economia do país, a maior parte do PIB brasileiro é composta por serviços. Esse estudo trabalhará com uma taxa de crescimento real de $2 \%$ após 2024 , mantendo um cenário mais conservador. O valor da taxa de crescimento "g" 
em perpetuidade deve ser ajustado a previsão de inflação de 2020 que está sendo prevista em $3,58 \%$ (BC, 2020).

Sendo assim, a taxa “g” em perpetuidade será de 5,58\% ajustada pela inflação prevista em 2020.

\subsubsection{Valor Presente do Fluxo de Caixa e Valor Empresarial}

O valor empresarial pode ser obtido através do desconto de cada fluxo de caixa gerado anualmente descontado pelo CAPM de 15,23\%, conforme tabela abaixo:

Tabela 7:

Valor Empresarial da empresa alvo pelo método FCD

\begin{tabular}{|c|c|c|c|}
\hline Ano & $\begin{array}{c}\text { Geração de Caixa (R\$ } \\
\text { mil) }\end{array}$ & $\begin{array}{l}\text { CAPM } \\
15,23 \%\end{array}$ & $\begin{array}{c}\text { Valor Presente Geração de Caixa } \\
\text { (R\$mil) }\end{array}$ \\
\hline 2020 & $497.798,05$ & 1 & $432.003,86$ \\
\hline 2021 & $539.662,87$ & 2 & $406.435,30$ \\
\hline 2022 & $585.048,52$ & 3 & $382.380,03$ \\
\hline 2023 & $634.251,10$ & 4 & $359.748,50$ \\
\hline 2024 & $687.591,61$ & 5 & $338.456,42$ \\
\hline $\begin{array}{l}\text { Perpetuidade } \\
\text { Valor }\end{array}$ & $7.125 .302,00$ & 6 & $3.043 .756,50$ \\
\hline Empresarial & & & $4.962 .780,61$ \\
\hline
\end{tabular}

Nota. Fonte: Tabela realizada a partir das projeções e estimações feitas neste estudo.

Por conseguinte, este estudo conclui que o valor empresarial da empresa alvo pelo método de Fluxo de Caixa Descontado é de R $4.962 .780,61$.

\subsubsection{Avaliação por Múltiplos}

\subsubsection{Determinação da Empresa Comparável}


A empresa alvo é do segmento de Equipamentos de Proteção Individual (EPI), largamente usado na maioria das indústrias do país, por esta razão a comparação ideal deveria ser baseada em uma empresa que fosse uma competidora direta. Este segmento está intimamente ligado ao desemprenho da economia brasileira, quando a economia vai bem, mais funcionários são contratados, produtos produzidos, serviços prestados, e consequentemente, a venda de EPIs aumenta, especialmente por ser um produto de uso obrigatório por lei nas empresas e serviços prestados no Brasil.

No Brasil, somente as americanas 3M e a MSA operam no país, e são de capital aberto. Este estudo escolheu a MSA para título de comparação, por ser a mais semelhante com a empresa alvo.

O valor de mercado da empresa MSA pode servir como uma referência para se entender o valor da empresa alvo deste estudo.

A informação financeira mais recente disponível é de 2018, com um valor de mercado para a MSA de US\$ 1.608.012.000,00

\subsubsection{Determinação da Variável de Comparação}

A escolha da variável de comparação é peça chave para uma avaliação bem fundamentada. Este estudo observou os seguintes indicadores financeiros da empresa MSA em sua publicação anual para o ano de 2018:

Patrimônio Líquido: US\$ 602.578.000,00

Lucro Operacional: US\$ 173.479.000,00

Valor de Mercado: US\$ 1.608.012.000,00

\subsubsection{Determinação do Valor Empresarial}

Conforme citado no Referencial Teórico deste estudo, o valor de uma empresa pelo método de múltiplos pode ser alcançado através da equação $\mathrm{Pi}, t=\mathrm{Xi}, \mathrm{t} \times \mathrm{Pj}, \mathrm{t}$. Como todas as variáveis da equação devem ser consideradas $X j, t$ no mesmo período $t$, então, será aplicado o valor de mercado da empresa MSA em 2018, e da empresa alvo no mesmo período, conforme demonstrado na tabela 8. Como as informações financeiras da empresa americana estão em 
dólares, será usada a cotação do dia de hoje, 13 de fevereiro de 2020, do dólar comercial: $\mathrm{R} \$ 4,35$

Tabela 8:

Valor Empresarial da Empresa Alvo em 2018

\begin{tabular}{|c|c|c|}
\hline Variável & Descrição & Valor (R\$mil) \\
\hline $\mathrm{Pj}, \mathrm{t}$ & Valor de Mercado(Empresa Comparável) & $6.994 .852,20$ \\
\hline $\mathrm{Xj}, \mathrm{t}$ & Lucro Operacional (Empresa Comparável) & $754.633,65$ \\
\hline $\mathrm{Xi}, \mathrm{t}$ & Lucro Operacional (Empresa Alvo) & $3.702,65$ \\
\hline$P i, t=X i, t x(P j, t) / X j, t)$ & Valor Empresarial (Empresa Alvo) & $34.320,59$ \\
\hline
\end{tabular}

Nota. Fonte: Tabela elaborada a partir das projeções e estimações desenvolvidas no presente estudo

O valor empresarial da empresa alvo é de $\mathrm{R} \$ 34.320 .590,00$

\subsection{Análise e Interpretação dos Resultados}

Os resultados obtidos neste capítulo, demonstram três conclusões bem diversas sobre o valor da empresa alvo deste estudo. A heterogeneidade das metodologias usadas para estimar cada valor reforça a ideia que não existe um modelo absoluto na avaliação empresarial, uma vez que se pode assimilar diferentes aspectos da empresa estudada. Mesmo com resultados discrepantes, os métodos aplicados contribuíram para uma análise profunda da empresa.

O primeiro método aplicado, o Contábil, demonstrou um valor decrescente nos anos de 2016 e 2017 e depois, um leve aumento em 2018. Isso refletiu o aporte de capital que a empresa fez por causa dos meses de prejuízo e falta de lucro. Isso é importante porque demonstra o histórico patrimonial do negócio. A limitação deste método, neste específico estudo, é que só se foi conseguido os dados de 2016 a 2018, justamente um período ruim da empresa. Até 2015, a empresa faturava quase que o dobro do que faturou no período estudado deste trabalho. A empresa alvo usa o Sistema de Lucro Presumido o que faz com que ela pague Imposto de Renda sobre o faturamento total independentemente se houver lucro ou não durante o período. 
Este estudo optou por não expor todo o Balanço Patrimonial dos anos de 20162018 por conter informações de cunho mais íntimo e estratégico da empresa. Esse método reflete apenas um retrato de um momento ou período e não capta o real potencial da empresa.

O segundo método usado foi o de Fluxo de Caixa Descontado, que também carece de poucos anos de informação financeira sobre a empresa o que faz com que seu potencial seja limitado. A avaliação foi feita em um momento difícil da Economia do Brasil que refletiu nos resultados da empresa alvo. Este método seria melhor aplicado em um momento em que tanto a empresa, quanto a Economia do Brasil, estivessem melhor. Assim, o resultado deste método estaria mais próximo de um valor mais justo da empresa alvo. O maior desafio neste método, foi a estimação do custo de capital próprio ajustado a realidade da empresa alvo. O CAPM ganhou duas variáveis que representam o risco adicional de investir no Brasil e num negócio pequeno. E somando a isso, o estabelecimento de um cenário conservador por causa da Economia brasileira que ainda não decolou.

No terceiro método, Avaliação por Múltiplos, a empresa mais semelhante no mercado brasileiro, que tem informações disponíveis e que é concorrente direta da empresa alvo deste estudo, é uma empresa grande (a MSA), que opera em todo o mundo e possui um leque bem maior de produtos (EPIs), o que limitou um pouco o método usado. Se houvesse uma empresa brasileira, que atuasse somente no território nacional, semelhante a MSA, com informações públicas, talvez, este modelo poderia ter dado um valor mais próximo do valor justo da empresa deste estudo. O resultado obtido foi um valor bem mais alto que os outros métodos. Isto pode sugerir também, que se estivéssemos em um cenário econômico diferente e se houvesse conseguido mais informações financeiras de outros anos passados (inclusive o de 2019), o método de Fluxo de Caixa Descontado poderia ter dado um valor maior e, portanto, mais próximo ao método de Avaliação por Múltiplos.

Os métodos usados neste estudo, ajudaram a fornecer visões complementares da empresa a fim de embasar o seu potencial econômico financeiro.

Este estudo opta por escolher o Método do Fluxo de Caixa Descontado, porém, para ser reutilizado em outro espaço de tempo. Será necessário, não só esperar uma melhora da Economia brasileira, mas também, não usar somente períodos de baixa produtividade da organização, como foi o caso deste estudo. Infelizmente, este estudo só conseguiu períodos críticos da empresa, o que pode não ter refletido a real potencialidade do negócio. Entendese, além disso, que o valor justo da empresa pode estar entre os métodos de FCD e dos Múltiplos, por conta desta limitação. Na atual conjuntura, tanto da empresa quanto da Economia do país, esse valor justo não está aparecendo no atual momento. Uma reaplicação 
de todos os métodos usados neste estudo em um outro espaço de tempo no futuro e com mais informações financeiras será mais bem aplicado e retratará melhor o valor justo da empresa.

Uma empresa de capital fechado não está precificada no mercado, logo, é essencial o uso de mais de um método para se avaliar seu valor justo. Os métodos usados neste estudo serão de grande contribuição para discussões, avaliações, mudanças de estratégias e reestruturações dentro da empresa alvo. 


\section{Conclusão}

O presente estudo pretendeu investigar os principais métodos de avaliação empresarial para uma empresa pequena, de capital fechado e familiar usando o Método Contábil, o Fluxo de Caixa Descontado e a Avaliação por Múltiplos, a fim de identificar a metodologia que melhor se adequa a realidade da empresa alvo. Foi utilizado um estudo de caso numa empresa real brasileira.

Para efetuar a análise pretendida, fez-se uma revisão da literatura em Finanças, para se entender e adaptar os modelos para a realidade do negócio da empresa em questão. Logo, constatou-se que havia poucos exemplos de pequenas empresas, sendo a maioria empresas multinacionais.

Mesmo assim, o processo de pesquisa demonstrou-se muito recompensador a respeito dos métodos científicos existentes e praticados, e também, sobre o entendimento da empresa quanto aos resultados em si. O Método Contábil demonstrou um PL que diminuiu e comprometeu o caixa da empresa, porém, ele somente reflete um período curto e difícil, onde teve-se que aportar dinheiro ao negócio. Nos anos anteriores ao deste estudo, a empresa faturava quase que o dobro até a crise de 2015 no Brasil. A empresa trabalha com o Sistema de Lucro Presumido, pagando IR independentemente de haver lucro ou não sobre o faturamento, oque também pode ser revisto no futuro. Esse estudo optou por não expor os Balanços Patrimoniais de 2016 a 2019, porém, o ciclo financeiro da empresa precisa ser revisto, ele não está sendo uma ferramenta estratégica. O Método Contábil não reflete o potencial econômico do negócio, apesar de ser amplamente usado tanto no mercado quanto na Academia, ele é limitado. O Fluxo de Caixa Descontado resultou num valor baixo também devido à falta de mais informações financeiras passadas e cenário econômico desfavorável. Se a análise tivesse sido feita em outro período, esta teria dado um valor mais alto e próximo ao seu potencial de gerar valor. Enquanto o Método dos Múltiplos revelou um valor bem superior aos outros dois, por ter sido comparado à uma empresa semelhante, mas, maior e multinacional o que limitou o método. Independentemente dos métodos e de ser um momento difícil, este estudo demonstra que a empresa não necessariamente fez e está fazendo estratégias para se defender da crise da Economia brasileira. A empresa deste estudo precisa, antes de ser avaliada novamente no futuro, ser reestruturada. Novas estratégias, alinhamento do seu ciclo financeiro, mudança de sindicato, mudanças de pessoal, governança corporativa, revisão dos contratos comerciais, uma cultura organizacional forte, bem definida e alinhada com os colaboradores, 
novo portfolio de produtos que o mercado está demandando, entre outros. Com isso, a empresa vai se levantar, e assim, poder ser reavaliada num outro momento, por um valor mais justo que reflita seu potencial. Uma potencial venda hoje, também não seria indicado porque possíveis investidores podem estar segurando seus caixas, avessos a riscos e/ou oferecendo um valor bem abaixo do mercado por conta do cenário econômico brasileiro. Este estudo recomenda reaplicar o método do Fluxo de Caixa Descontado em outro momento no futuro, onde haja mais estabilidade na Economia brasileira e mudanças internas na empresa seja feitas.

\subsection{Sugestões e Recomendações para Novas Pesquisas}

Conforme já dito anteriormente, a aplicação de diferentes métodos de avaliação empresarial é fundamental para o conhecimento da realidade financeira da empresa. Porém, este trabalho não abordou outros modelos diferentes como Opções Reais e o Valor Econômico Agregado (EVA)

O próximo passo poderia ser o estudo de Opções Reais e o EVA para pequenas empresas de capital fechado e/ou familiares. Quanto mais modelos forem estudados e comparados, melhor será a compreensão da realidade da empresa e seu valor justo. 


\section{Referências Bibliográficas}

AMARAL, Marco. Tipos de risco na atividade bamcária. Revista Revisores 3 Auditores, $p$. 36, Abril/Junho 2015 [online] Disponível em

http://www.oroc.pt/fotos/editor2/Revista/69/Gestao.pdf Acesso em: 28 de Outubro de 2019.

ASSAF NETO, Alexandre. Finanças Corporativas e valor. São Paulo: Atlas, 2008.

BANCO CENTRAL DO BRASIL. Cotações e boletins. Brasília, 2020 [online] Disponível em: de Acesso em janeiro de 2020. https://www.bcb.gov.br

BANCO CENTRAL DO BRASIL. Focus - Relatório de Mercado. Brasília, 2019 [online] Disponível em: https:/www.bcb.gov.br/content/publicacoes/boxrelatoriosinf/ri201912b1p.pdf Acesso em: dezembro 2019

BANCO CENTRAL DO BRASIL. Risco País. Brasília, 2016 [online] Disponível em: Acesso em: dezembro de 2019.

BNDES. Apoio às Micro, Pequenas e Médias Empresas, 2015 [online] Disponível em: Acesso em: dezembro de 2019.

BERK, J.; DEMARZO, P. Finanças Empresariais. Porto Alegre: Bookman, 2009. 1048 p.

BRASIL. Lei n. 11.638, de 28 de dezembro de 2007. Altera e revoga dispositivos da Lei no 6.404, de 15 de dezembro de 1976, e da Lei no 6.385, de 7 de dezembro de 1976, e estende às sociedades de grande porte disposições relativas à elaboração e divulgação de demonstrações financeiras. Disponível em: $<$ http://www.planalto.gov.br/ccivil_03/_ato2007- 2010/2007/lei/111638.htm>. Acesso em: 30 de outubro de 2019.

BRANDÃO, J. W.. Análise dos Múltiplos de Empresas Brasileiras Segundo o Modelo Revaam. Revista de Finanças Aplicadas, V.1, 2015. P. 1-32, 2015.

BREALEY, Richard A.; MYERS, Stewart C.; ALLEN, Franklin. Princípios de Finanças Corporativas. 10. ed. Porto Alegre: Editora McGraw-Hill, 2013. 875 p.

BRIGHAM, E.; EHRHARDT, M.; Administração Financeira teoria e prática. 3.ed. São Paul: Editora Cengage Learning, 2017.933 p.

BROOKS, C. Introductory Econometrics for Finance. 3rd Edition. United States of America, NY: Cambridge University Press, May 2, 2014. 710 p. 
CERBASI, G. P.. Metodologias para determinação do valor das empresas, São Paulo, 2003. Dissertação (Mestrado em Administração) - USP.

CUNHA, M.; MARTINS, E.; ASSAF NETO, A. Avaliação de Empresas no Brasil pelo Fluxo de Caixa Descontado: Evidências Empíricas sob o Ponto de Vista do Desempenho Econômico-Financeiro, Tese de Doutorado, USP 2011. Disponível em: $<$ https://teses.usp.br/teses/disponiveis/12/12136/tde-08022012-181605/en.php>

Conselho Federal de Contabilidade. Resolução CFC n.o 847/99. Brasília, 1999 Disponível em: < http:// http://www1.cfc.org.br/sisweb/SRE/docs/RES_847.pdf >. Acesso em: 30 de outubro de 2019.

CORREIA, J. F. Revisão teórica de modelos de avaliação de empresas. Rev. Cent. Ciênc. Admin., Fortaleza, v. 11, n. 2, p. 165-175, dez 2005.

CRESWELL, John W. Projeto de Pesuisa, métodos qualitativo, quantitativo e misto. $3^{\text {a }}$ Ed. Porto Alegre: Artmed, 2010. 296p.

DAMODARAN, A. Valuation Approaches and Metrics: A Survey of the Theory and Evidence. Foundations and Trend in Finance, New York, v. 1, n. 8, 2005

DAMODARAN, A. Equity Risk Premiums (ERP): Determinants, Estimation and Implications - The 2017 Edition. Stern School of Business, Mar. 2017. Disponível em: < https://papers.ssrn.com/sol3/papers.cfm?abstract_id=2947861>. Acesso em: 30 de outubro de 2019.

DAMODARAN, ASWATH. Implied ERP by month for previous months, 2019. Disponível em: <http://pages.stern.nyu.edu/ adamodar/New_Home_Page/home.htm $>$. Acesso em: $30 \mathrm{de}$ outubro de 2019.

FAMA, E., KENNETH R., The Capital Asset Pricing Model: Theory and Evidence, Center for Research in Security Prices, Journal of Economic Perspective, v. 18, n. 3, p. 25-46, janeiro de 2004

FERNÁNDEZ, P. Company valuation methods. The most common errors in valuations. IESE Business School, 2001. Disponível em: < http://www.iese.edu/research/pdfs/di-0449e.pdf $>$. Acesso em: 30 de outubro de 2019. 
GARRÁN, F. Metodologias em uso no Brasil para a determinação do custo de capital próprio para a avaliação de ativos por fluxo de caixa descontado. Dissertação de Mestrado. USP 2006. Disponível em: < https://teses.usp.br/teses/disponiveis/12/12139/tde-02022007132550/publico/Custocapital.pdf $>$. Acesso em 4 de novembro de 2019.

GITMAN, Lawrence J. Princípios de Administração Financeira. 2a. ed. Trad. Antonio Zoratto Sanvicente. São Paulo: Pearson Addison Wesley, 2004.

INVESTING.COM https://m.investing.com/equities/mine-safety-appliances-comp Acesso em 28 de janeiro de 2020 .

KOLLER, T; GOEDHART, M; WESSELS, D. Valuation: measuaring and managing the value of companies. Fith Edition McKinsey \& Company, New Jersey, 2010.

LIU, J., NISSIM, D. \& THOMAS, J. (2002) “Equity Valuation Using Multiples”. Journal of Accounting Research, 40 (1), 135-172.

MARKOWITZ, H. Portfolio Selection: Efficient Diversification of Investments. Cowles Foundation for Reserach in Economics at Yale University, 1959.

MARTELANC, R.; TRIZZI, S. J; PACHECO, S. A. A.; PASIN, M. R. A. Utilização de metodologias de avaliação de empresas: resultados de uma pesquisa no Brasil. Seminário em Administração, FEA/USP-SEMEAD, VII Anais, São Paulo, 2005.

MARTINS, E. Avaliação de Empresas: da Mensuração Contábil à Econômica. Caderno de Estudos, v 13, n. 24, p. 28-37, julho/dezembro 2000.

MINISTÉRIO DA FAZENDA. Taxa de Juros Selic. 2019. Disponível em: $<$ http://idg.receita.fazenda.gov.br/orientacao/tributaria/pagamentos-e- parcelamentos/taxade-juros-selic>. Acesso em: 18 de Outubro de 2019.

MîNJINA, D. Relative Performance of Valuation using Multiples. The Review of Finance and Banking, v. 01, n. 1, p. 035-053, 2009.

OECD. Inflation Forecast. 2019. Disponível em: < https://data.oecd.org/price/inflationforecast.htm>. Acesso em: 03 de dezembro de 2019.

PORTAL BRASIL. Risco País. 2019. Disponível em: $<$ https://www.portalbrasil.net/2017/indices/risco_pais_comparativo_dezembro.ht m>. Acesso em: 07 de novembro de 2019.

PRADO, M. F. Estudo de caso de empresa familiar: um comparativo dos métodos de valuation. Revista de Administração da UNIMEP, v.9, n.2, p. 47- 67, 2011.

MSASAFETY.COM 2020. Disponível em: https://investors.msasafety.com/staticfiles/d183a4e0-18ef-4d9c-b272-ee01018ebbc5 Acesso em 7 de fevereiro de 2020. 
OECD, Prices Inflation Forecast, 2020. Disponível em: $<$ https://data.oecd.org/price/inflationforecast.htm>

PORTAL BRASIL. Risco País. 2019. Disponível em: $<$ https://www.portalbrasil.net/2018/indices/risco_pais_comparativo_outubro.html $>$ Acesso em: 7 de fevereiro de 2020.

SALIBA, R. "Aplicação de Modelos de Avaliação por Múltiplos no Brasil" Rio de Janeiro, 2005. Dissertação de Mestrado, FGV. Disponível em: < https://bibliotecadigital.fgv.br/dspace/bitstream/handle/10438/308/2019.pdf $>$. Acesso em 6 de novembro de 2019.

SAURIN, V. Estudo dos modelos de avaliaçao de empresas com base na metodologia do fluxo de Caixa descontado: Estudo de caso. Revista de Ciências da Administração, v. 9, n. 18, p. 123-148, maio/agosto. 2007.

SHARPE, W. Capital Asset Prices: A Theory of Market Equilibrium under Conditions of Risk. The Journal of Finance, v. 19, n. 3, p. 425-442, Sep, 1964.

SOUTE, D., MARTINS, E., SCHVIRCK, MACHADO, M. Revista UnB Contábil, v. 11, n. $1-2$, p.1-17, jan./dez. 2008.

U.S DEPARTMENT OF THE TREASURY. Daily Treasury Yield Curve Rates. 2019. Disponível em: https://www.treasury.gov/resource-center/data-chart-center/interestrates/pages/TextView.aspx?data=yield Acesso 12 de novembro de 2019.

WORLD BANK, 2019, Listed Domestic Companies Total, Brazil [online] Disponível https://data.worldbank.org/indicator/CM.MKT.LDOM.NO?locations=BR Acesso em: 28 de Outubro de 2019. 